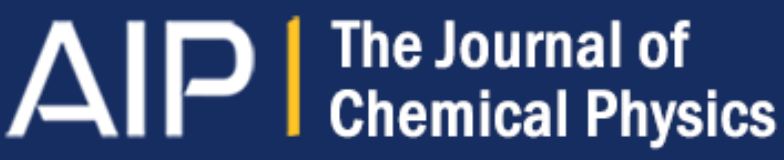

\section{UV photodissociation of methyl bromide and methyl bromide cation studied by velocity map imaging}

Valérie Blanchet, Peter C. Samartzis, and Alec M. Wodtke

Citation: The Journal of Chemical Physics 130, 034304 (2009); doi: 10.1063/1.3058730

View online: http://dx.doi.org/10.1063/1.3058730

View Table of Contents: http://scitation.aip.org/content/aip/journal/jcp/130/3?ver=pdfcov

Published by the AIP Publishing

\section{Articles you may be interested in}

Ab initio study of methyl-bromide photodissociation in the $A^{\sim}$ band

J. Chem. Phys. 130, 244305 (2009); 10.1063/1.3154140

Nonadiabatic dynamics in the photodissociation of I C H 2 C N at 266 and $304 \mathrm{~nm}$ studied by the velocity map imaging

J. Chem. Phys. 124, 124307 (2006); 10.1063/1.2167748

Velocity-map imaging study of the photodissociation of acetaldehyde

J. Chem. Phys. 122, 124303 (2005); 10.1063/1.1861886

A velocity map ion-imaging study on ketene photodissociation at 208 and $213 \mathrm{~nm}$ : Rotational dependence of product angular anisotropy

J. Chem. Phys. 122, 104309 (2005); 10.1063/1.1858435

The photodissociation of the vinyl radical ( $\mathrm{C} 2 \mathrm{H} 3$ ) at $243 \mathrm{~nm}$ studied by velocity map imaging

J. Chem. Phys. 110, 4248 (1999); 10.1063/1.478307

How can you REACH $100 \%$

of researchers at the Top 100

Physical Sciences Universities?

With The Journal of Chemical Physics.

AIP $\begin{aligned} & \text { The Journal of } \\ & \text { Chemical Physics }\end{aligned}$

THERE'S POWER IN NUMBERS. Reach the world with AIP Publishing.

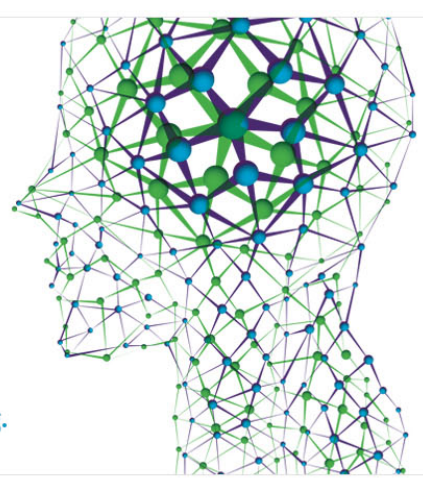




\title{
UV photodissociation of methyl bromide and methyl bromide cation studied by velocity map imaging
}

\author{
Valérie Blanchet, ${ }^{1,2, a)}$ Peter C. Samartzis, ${ }^{3}$ and Alec M. Wodtke ${ }^{3}$ \\ ${ }^{1}$ Laboratoire Collisions Agrégats Réactivité, IRSAMC, Université de Toulouse, UPS, \\ F-31062 Toulouse, France \\ ${ }^{2}$ CNRS, UMR 5589, F-31062 Toulouse, France \\ ${ }^{3}$ Department of Chemistry and Biochemistry, University of California, Santa Barbara, \\ California 93106, USA
}

(Received 30 October 2008; accepted 8 December 2008; published online 20 January 2009)

\begin{abstract}
We employ the velocity map imaging technique to measure kinetic energy and angular distributions of state selected $\mathrm{CH}_{3}\left(v_{2}=0,1,2,3\right)$ and $\mathrm{Br}\left({ }^{2} P_{3 / 2},{ }^{2} P_{1 / 2}\right)$ photofragments produced by methyl bromide photolysis at $215.9 \mathrm{~nm}$. These results show unambiguously that the $\mathrm{Br}$ and $\mathrm{Br}^{*}$ forming channels result in different vibrational excitations of the umbrella mode of the methyl fragment. Low energy structured features appear on the images, which arise from $\mathrm{CH}_{3} \mathrm{Br}^{+}$photodissociation near $330 \mathrm{~nm}$. The excess energy of the probe laser photon is channeled into $\mathrm{CH}_{3}{ }^{+}$vibrational excitation, most probably in the $\nu_{4}$ degenerate bend. (C) 2009 American Institute of Physics.
\end{abstract}

[DOI: $10.1063 / 1.3058730]$

\section{INTRODUCTION}

As in all methyl halides or alkyl and aryl halides, the $\widetilde{A} \leftarrow X$ band of $\mathrm{CH}_{3} \mathrm{Br}$, characterized by excitation to the antibonding $\sigma^{*}$ orbital localized along the $\mathrm{C}-\mathrm{Br}$ bond, exhibits a broad photodissociation continuum. This diffuse band in the ultraviolet range, environmentally relevant to atmospheric chemistry, ${ }^{1,2}$ is characterized by a prompt dissociation via two dominant photofragmentation pathways,

$$
\begin{array}{r}
\mathrm{CH}_{3} \mathrm{Br}+\hbar \nu \rightarrow \mathrm{CH}_{3}+\mathrm{Br}\left({ }^{2} P_{3 / 2}\right), \\
\mathrm{CH}_{3}+\mathrm{Br}^{*}\left({ }^{2} P_{1 / 2}\right) .
\end{array}
$$

The spin-orbit coupling of the halide lifts degeneracy to give rise to three optically allowed electronic transitions to states which are, in order of increasing energy, the ${ }^{3} Q_{1},{ }^{3} Q_{0}$, and ${ }^{1} Q_{1}$ states. In the $C_{3 v}$ geometry, dissociation via the ${ }^{X} Q_{1}$ (with $X=1$ or 3 ) and ${ }^{3} Q_{0}$ states correlates adiabatically to $\operatorname{Br}\left({ }^{2} P_{3 / 2}\right)$ and $\operatorname{Br} *\left({ }^{2} P_{1 / 2}\right)$, respectively. These transitions can be identified through the orientation of the transition electric dipole moment relative to the $\mathrm{C}-\mathrm{Br}$ bond: the ${ }^{X} Q_{1}$ transitions are perpendicular while the ${ }^{3} Q_{0}$ transition is parallel. The dipole moments of ${ }^{X} Q_{1} \leftarrow \tilde{X}$ arise from intensity borrowing from Rydberg states lying $\sim 1 \mathrm{eV}$ higher in energy, ${ }^{3}$ similar to $\mathrm{CH}_{3} \mathrm{I}{ }^{4}$ Near the absorption maximum of the $\widetilde{A} \leftarrow X$ band, perpendicular and parallel transitions of similar probability are allowed, ${ }^{5}$ in contrast to the $\tilde{A} \leftarrow X$ band in $\mathrm{CH}_{3} \mathrm{I}$. The Franck-Condon region is centered around an equilibrium $\mathrm{C}-\mathrm{Br}$ bond distance of $1.95 \pm 0.1 \AA{ }^{6,7}$ Breaking $C_{3 v}$ symmetry, induced for instance by the rocking mode $\nu_{6}$, leads to coupling between ${ }^{1} Q_{1}$ and ${ }^{3} Q_{0}$ surfaces opening possibly nonadiabatic transitions that strongly influence the product branching ratio between the two spin-orbit channels. This

${ }^{a)}$ Electronic mail: val@irsamc.ups-tlse.fr. can be quite different for alkyl halides of $C_{s}$ symmetry for which in some cases no avoided crossing emerges, for example in $\mathrm{CH}_{2} \mathrm{ClBr}$ (Ref. 8) or in $\mathrm{C}_{3} \mathrm{H}_{7} \mathrm{Br}^{9,10}$ The curve crossing in $\mathrm{CH}_{3} \mathrm{Br}$ has been calculated to occur at a $\mathrm{C}-\mathrm{Br}$ internuclear distance around $2.445 \AA{ }^{6}$. Its probability has been experimentally determined. ${ }^{5}$ In all these systems, the ${ }^{3} Q_{1}$ state seems to be decoupled from the ${ }^{3} Q_{0}$ state. ${ }^{11}$ Many aspects of this photodissociation system were summarized before. $^{12}$

A study carried out around the absorption maximum of the $\widetilde{A} \leftarrow X$ band at $202 \mathrm{~nm}$ and analyzing the kinetic energy distribution of $\mathrm{Br}$ fragments suggested that the internal energy of $\mathrm{CH}_{3}$ is imparted into the $\nu_{2}$ umbrella mode and that the vibrational excitation was different for the two spin-orbit channels. ${ }^{13}$ The $\operatorname{Br}\left({ }^{2} P_{3 / 2}\right)$-producing channel appears to peak around $v_{2}=3$, while the $\operatorname{Br}^{*}\left({ }^{2} P_{1 / 2}\right)$-producing channel peaks around $v_{2}=1$ or $2 .^{13}$ Similar conclusions were reached through use of photofragment imaging of product $\mathrm{Br}$ atoms $\left(\lambda_{\text {photolysis }} \sim 205 \mathrm{~nm}\right)$ (Ref. 14) and of $\mathrm{CH}_{3}$ by nonresonant multiphoton ionization $\left(\lambda_{\text {photolysis }} \sim 226-218 \mathrm{~nm}\right){ }^{5}$ Despite a lack of state specific detection of $\mathrm{CH}_{3}$, these studies suggest that the umbrella mode vibrational distribution of $\mathrm{CH}_{3}$ follows the general rules that are $v_{2}^{\max }>0$ and $v_{2}^{\max }(\mathrm{Br})$ $>v_{2}^{\max }\left(\mathrm{Br}^{*}\right)$.

Similar conclusions have been derived from observations in other molecules, such as $\mathrm{CH}_{3} \mathrm{I}, \mathrm{CF}_{3} \mathrm{Br}$, and $\mathrm{CH}_{3} \mathrm{Cl}^{12,15}$ As a function of the photolysis energy, the vibrational distribution of the umbrella mode is not expected to change drastically. ${ }^{16}$ Methyl radical has a planar equilibrium geometry, while $\mathrm{CH}_{3}$ in the ground electronic state of $\mathrm{CH}_{3} \mathrm{Br}$ has a pyramidal geometry with an equilibrium angle around $111.5^{\circ} .^{6,7}$ In the case of dissociation of $\mathrm{CH}_{3} \mathrm{I}$ in the $\widetilde{A} \leftarrow \tilde{X}$ band, the vibrational distribution is frequently rationalized by an abrupt change from pyramidal to planar geometry at the seam of the ${ }^{1} Q_{1^{-}}{ }^{3} Q_{0}$ curve crossing, so that any trajec- 
tory going through the nonadiabatic transition, which leads to $\operatorname{Br}\left({ }^{2} P_{3 / 2}\right)$, receives extra umbrella mode excitation. ${ }^{11}$ In other words, if the Br producing channel is populated significantly by this nonadiabatic transition, its umbrella activity is expected to be more excited than that of the Br* producing channel for which the pyramidal to planar relaxation occurs more gradually and adiabatically along the ${ }^{3} Q_{0}$ surface.

Another suggested explanation not involving the ${ }^{1} Q_{1^{-}}{ }^{3} Q_{0}$ curve crossing relies on the difference in slope of the potential energy surface of ${ }^{1} Q_{1}$ and ${ }^{3} Q_{0}$ states as a function of the distance between $\mathrm{C}$ and the center of mass of the three $\mathrm{H}$ atoms in the vicinity of the Franck-Condon region. The ${ }^{1} Q_{1}$ surface is steeper, therefore the umbrella excitation will have less time to relax from pyramidal to planar geometry compared to trajectories following the ${ }^{3} Q_{0}$ state. ${ }^{14,16,17}$ In all these studies, with the exception of some methyl substituted bromides, ${ }^{18}$ it has been pointed out that the methyl fragment is likely to be rotationally cold due to a weakly bent excited state for both surfaces. This is confirmed by studies of the photodissociation of rotationally state-selected methyl bromide between 213 and $235 \mathrm{~nm} .{ }^{19}$ The rotational distribution of $\mathrm{CH}_{3}$ photofragments extends up to $N=6$ for photolysis at $230 \mathrm{~nm}$ and slightly higher- $N=9-$ when photolysis is performed at $212.8 \mathrm{~nm}$, with almost no difference between a $\mathrm{Br}^{*}$ and $\mathrm{Br}$ channels. ${ }^{19}$ This experiment has investigated mainly the production of vibrational ground state methyl and the influence of deuteration. Similar work has been performed on the extreme red wing $(240-280 \mathrm{~nm})$ of the $\widetilde{A} \leftarrow \tilde{X}$ absorption band with an effusive molecular beam. ${ }^{20}$

We report here kinetic energy and angular distributions of bromine and methyl fragments recorded by the velocity map imaging technique following photodissociation of $\mathrm{CH}_{3} \mathrm{Br}$ at $215.9 \mathrm{~nm}$. The vibrational states of methyl radicals were probed by resonant enhanced multiphoton ionization $\left(2+1\right.$ REMPI) via the intermediate Rydberg $3 p{ }^{2} A_{2}^{\prime \prime}$ state. At this photolysis energy the direct absorption ratio of parallel to perpendicular excitation is around $\left[{ }^{3} Q_{0}\right] /\left[{ }^{3} Q_{1}\right.$ $\left.+{ }^{1} Q_{1}\right]=1.5$. ${ }^{5}$ We have recorded velocity map images of individual vibrational states of $\mathrm{CH}_{3}$ excited in the $\nu_{2}$ umbrella mode up to $\nu_{2}=3$, in contrast to previous experiments in which only the kinetic energy distribution of $\mathrm{Br}$ fragments was available ${ }^{14,20}$ or where $\mathrm{CH}_{3}$ was detected only in its ground vibrational state ${ }^{19}$ or without vibrational state selection. ${ }^{5}$ The images show two features that can be assigned to formation of $\mathrm{Br}$ and $\mathrm{Br}^{*}$. We are thus able to unambiguously confirm the prior interpretation of $\mathrm{Br}$ atom velocity maps and photofragment images which implicated a greater degree of $\nu_{2}$-vibrational excitation in the Br-forming channel.

We also observe for the first time, the photolysis of $\mathrm{CH}_{3} \mathrm{Br}^{+}$cation in the near UV. This results in a highly structured velocity map image, which can be assigned to progression of high vibrational states of the $\mathrm{CH}_{3}{ }^{+}$product ion. An indirect photodissociation mechanism involving nonadiabatic coupling is proposed.

\section{EXPERIMENTAL SETUP}

Methyl bromide with $99 \%$ purity containing the natural abundance of bromine isotopes was used without further pu- rification. A $10 \% \mathrm{CH}_{3} \mathrm{Br} / \mathrm{He}$ mixture at 0.5 bar stagnation pressure expanded supersonically through a solenoid pulsed valve (General Valve Series 9, Parker Hannifin Corp.) with a $0.8 \mathrm{~mm}$ orifice to produce a $300 \mu$ s long pulsed molecular beam. After passing through a skimmer, the molecular beam was collimated to $1 \mathrm{~mm}$ and entered the ion optical region of a standard velocity mapping ion source. ${ }^{21}$ The molecular beam was then intersected midway between the repeller and the extractor plates by two counter propagating laser beams both perpendicular to the time-of-flight axis, which dissociated $\mathrm{CH}_{3} \mathrm{Br}$ and selectively ionized the fragment of choice. The ions produced were accelerated before being mass selected at the end of a $1 \mathrm{~m}$ long time-of-flight tube by gating the gain of a $7.5 \mathrm{~cm}$ diameter dual microchannel plate (MCP)/phosphor imaging detector (Burle ElectroOptics). The gating voltage pulse was applied on the front MCP and was typically $-500 \mathrm{~V}$ over $170 \mathrm{~ns}$. The images were recorded typically over 36000 laser shots by imaging software (Davis, LaVision) on a $(640 \times 480)$ charge-coupled device (CCD) camera (XC7500, Sony) coupled to a frame grabber (PCimage SG, Matrix Vision). The repeller voltage was fixed at $5 \mathrm{kV}$ for the methyl fragments so that the detector surface is $80 \%$ filled and at $3 \mathrm{kV}$ for the $\mathrm{Br}$ fragment to enlarge the images. The optimal velocity mapping condition corresponds to an extractor/repeller voltage ratio of 0.7 . In the kinetic energy range explored here, 1 pixel on the image corresponds roughly to $30 \mathrm{meV}$ shift.

The repetition rate is fixed at $10 \mathrm{~Hz}$ by the photodissociation laser. The $215.9 \mathrm{~nm}$ photolysis beam was produced by frequency doubling the output of a Nd:YAG (yttrium aluminum garnet) (Continuum Powerlite 7010, third harmonic at $355 \mathrm{~nm}$ ) pumped dye laser (Sirah) operating on Stilbene, through a $7 \mathrm{~mm}$ beta barium borate (BBO) crystal. The 1 $\mathrm{mJ} /$ pulse output was focused by a $50 \mathrm{~cm}$ focal length lens on the molecular beam. The photofragments were selectively ionized by a REMPI probe laser. $\operatorname{Br}\left({ }^{2} P_{3 / 2}\right)$ photofragment was the only species probed by a single laser scheme; namely, photodissociation and detection by $(2+1)$ REMPI via the ${ }^{4} D_{5 / 2}^{0}$ state at $215.9 \mathrm{~nm}$. The methyl photofragments were photoionized by $(2+1)$ REMPI via the $3 p^{2} A_{2}^{\prime \prime}$ Rydberg state, ${ }^{22,23}$ using the doubled (approximately $340 \mathrm{~nm}$ ) output of a dye laser (Continuum ND6000) operating on a mixture of DCM/LDS698 and pumped by the second harmonic of a Nd:YAG laser (Continuum Powerlite 8020). About $4 \mathrm{~mJ} /$ pulse of this probe laser light was focused by a $60 \mathrm{~cm}$ focal length lens onto the molecular beam. Vibrationally excited states of $\mathrm{CH}_{3}$ were probed via $2_{v}^{v}$ two-photon transition up to $v=3$. The REMPI laser for each of those transitions was tuned to the transition maximum, which corresponds to a $Q$ branch. The $\operatorname{Br}^{*}\left({ }^{2} P_{1 / 2}\right)$ photofragments were photoionized by $(2+1)$ REMPI via the ${ }^{2} P_{1 / 2}^{0}$ state at $238.6 \mathrm{~nm}$. To produce this wavelength, the doubled output of a dye laser (Continuum ND6000) operating with R640 and pumped by the second harmonic of an Nd:YAG laser (Continuum Powerlite 8020) was mixed with the pump laser's fundamental of $1064 \mathrm{~nm}$.

In the case of methyl ion detection, no ion background was observed with the REMPI laser alone but the dissociation laser produces some background ions via a one-photon 
TABLE I. State specific imaging results. Intermediate states through which resonant ionization of photofragments has been recorded, $\mathrm{Br}^{*} / \mathrm{Br}$ yield as shown in Fig. 2, width of Lorentzian for the translational energy, and vibrational distributions deduced from fits shown in Fig. 3.

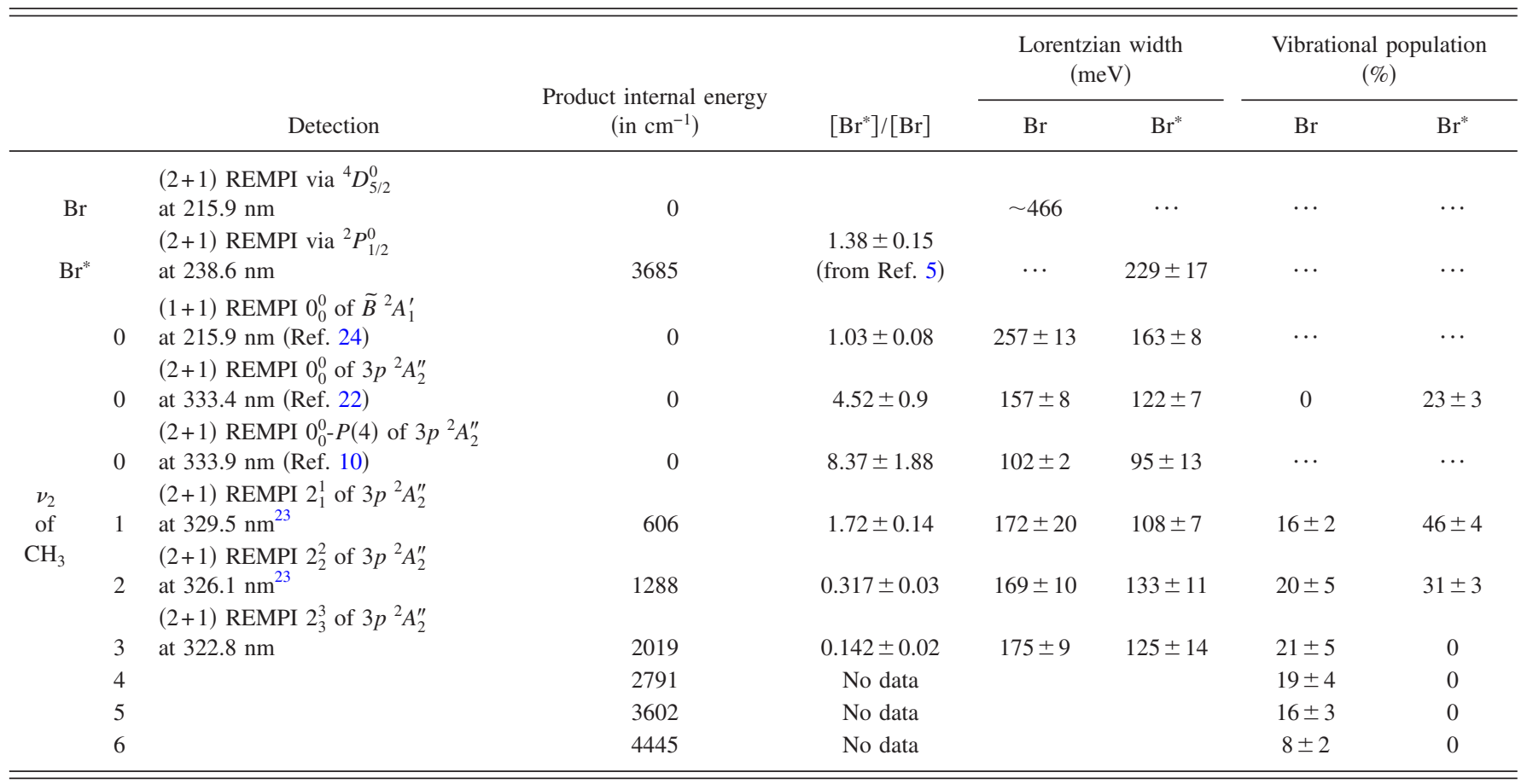

transition to the $\widetilde{B}^{2} A_{1}^{\prime}$ state of $\mathrm{CH}_{3}$, followed by absorption of a second photon ionizing $\mathrm{CH}_{3} \cdot{ }^{24} \mathrm{~A}$ background is also present on the $\mathrm{Br}^{*}$ image as the $\widetilde{A} \leftarrow X$ band of $\mathrm{CH}_{3} \mathrm{Br}$ is excited not only by the photolysis laser at $215.9 \mathrm{~nm}$ but also by the REMPI laser at $238.6 \mathrm{~nm}$. In each case, background contributions were recorded independently and carefully subtracted. Typically these sources of background were around $20 \%$ of the signal for methyl detection and $50 \%$ of the signal for $\mathrm{Br}^{*}$ detection. Table I summarizes the resonant states and the corresponding REMPI wavelengths used for all species detected in this experiment.

The spatial overlap between the laser and molecular beams was optimized using an NO molecular beam and nonresonant multiphoton ionization. To ensure detection of all photofragments, the typical delay introduced between the two lasers did not exceed 5 ns. Both laser polarizations were parallel to the detector plane in order to maintain cylindrical symmetry required for the inverse Abel transformation. Reconstruction of the three-dimensional-velocity map led to fragment kinetic energy and angular distributions. The dissociation energy assumed in this work was reported by Janssen et $a l .{ }^{19}$ to be $D_{0}=2.901 \pm 0.016 \mathrm{eV}$.

\section{RESULTS AND DISCUSSION}

Velocity map images are highly structured, reflecting two different photochemical pathways in $\mathrm{CH}_{3} \mathrm{Br}$. The first reflects the photochemistry of the $\tilde{A} \leftarrow X$ band in methyl bromide neutral. The second is due to the photodissociation of $\mathrm{CH}_{3} \mathrm{Br}^{+}$around $330 \mathrm{~nm}$. Both of these appear to exhibit rich electronically nonadiabatic behavior as discussed in Sec. III A for the $\mathrm{CH}_{3} \mathrm{Br}$ and in Sec. III B for its cation, respectively.

\section{A. Methyl bromide \\ 1. Experimental images}

Figure 1 shows typical images obtained for $m / z=15$ $\left(\mathrm{CH}_{3}{ }^{+}\right)$and $m / z=79\left(\mathrm{Br}^{+}\right)$. Figure 1(a) shows a one-color experiment using only the photolysis laser at $215.9 \mathrm{~nm}$ and is representative of some of the general observations of this work. Here one sees two sharp concentric rings at the outer edge of the image, which arise when the methyl fragment is unintentionally ionized via the $R$-branch of the $\left(\widetilde{B}^{2} A_{1}^{\prime}, 0_{0}^{0}\right)$ transition. The two outer rings correspond to the two $\mathrm{Br}$ spinorbit channels in $\mathrm{CH}_{3} \mathrm{Br}$ photolysis at $215.9 \mathrm{~nm}$. For all intents and purposes, this image is background and no attempt was made to analyze its information content. Rather, this background is subtracted from methyl images obtained in two-color experiments. Figures 1(b)-1(e) show these results after background subtraction. Here, one also sees two concentric rings at the perimeter of the image, which reflect the velocity and angular distributions of specific vibrational states of $\mathrm{CH}_{3}$ produced in the $215.9 \mathrm{~nm}$ photolysis of $\mathrm{CH}_{3} \mathrm{Br}$. Here $\mathrm{CH}_{3}$ is detected by $2+1$ REMPI via the $3 p^{2} A_{2}^{\prime \prime}$ Rydberg state. ${ }^{25}$ One also sees a sequence of features closer to the center of the images, which arise from $\mathrm{CH}_{3}{ }^{+}$produced in photodissociation of $\mathrm{CH}_{3} \mathrm{Br}^{+}$, which is itself produced by two-photon nonresonant ionization at $215.9 \mathrm{~nm}$. We return to a discussion of this process later in Sec. III B.

The images shown in Figs. 1(b)-1(e) have been recorded with the REMPI laser tuned to peak of the sharp $Q$-branches of the $\left(3 p^{2} A_{2}^{\prime \prime}, 2_{v}^{v}\right)$ system. Images recorded with or without scanning over the $Q$-branch profile were found to be identical, indicating that no $\mathrm{CH}_{3}$ rotational selectivity is possible under our conditions. Two color images of $\operatorname{Br}\left({ }^{2} P_{3 / 2}\right)$ and $\operatorname{Br}\left({ }^{2} P_{1 / 2}\right)$ fragments, ionized by $2+1$ REMPI, are also shown in Figs. 1(g) and 1(h), respectively. 
(a) 0

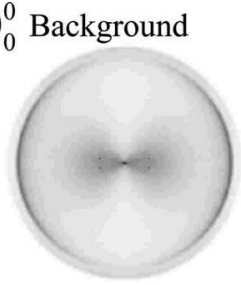

(c) $2_{1}^{1}$

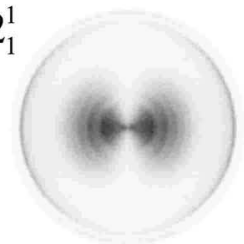

(e) $2_{3}^{3}$

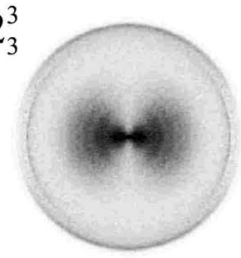

(g) $\mathrm{Br}$

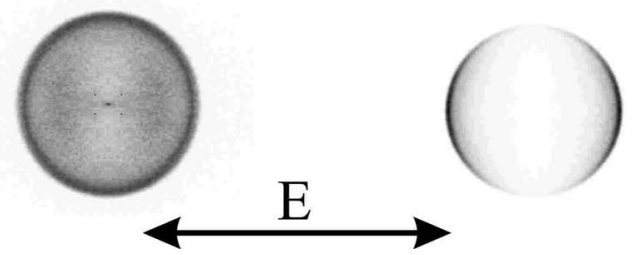

FIG. 1. Images of methyl radicals [(a)-(f)] produced from the $215.9 \mathrm{~nm}$ photolysis laser with background (a) subtracted. The images were respectively acquired over 12000 (b) and 36000 [(a), and (c)-(f)] laser shots. Images of bromine fragments produced in $(\mathrm{g}) \mathrm{Br}$ and $(\mathrm{h}) \mathrm{Br}^{*}$ states. The images are presented in 0-255 grayscale with the darkest shade corresponding to the maximum of the signal.

As $v_{2}$ umbrella excitation increases in these experiments, the signal intensity decreases due to a faster predissociation of $\mathrm{CH}_{3}$ in the intermediate $3 p^{2} A_{2}^{\prime \prime}$ state used for REMPI detection. ${ }^{26}$ Consequently, the origin band image of $\mathrm{CH}_{3}$ [Fig. 1(b)] is an average over 12000 laser shots compared with 36000 for the others. This predissociation combined with the other uncertainties associated with use of a structureless $Q$ branch for REMPI detection make it impossible to derive the $\mathrm{CH}_{3} v_{2}$ vibrational population distribution based on intensities of the images. However, if we assume that the energy distribution of bromine fragments reflects only umbrella mode activity, we can reconstruct the $v_{2}$ vibrational distribution. To test this assumption we probed other vibrational states, for example the symmetric $\mathrm{CH}$ stretch mode $\nu_{1}$. Normally, the excitation of symmetric the $\mathrm{CH}$ stretching mode, $\nu_{1}(372 \mathrm{meV})$, cannot be probed via the $\mathrm{Q}$ branch of the $1_{1}^{1}$ band (at $333.9 \mathrm{~nm}$ ) as it overlaps the $P(4) 0_{0}^{0}$ band. ${ }^{10,23,27}$ However, the translational energy released in the simultaneously detected channels is large enough that they can be identified and separated in this imaging experiment. The excess energy for the methyl fragment excited by one quantum of $\nu_{1}$, following dissociation at $215.9 \mathrm{~nm}$, is 2.01 $\mathrm{eV}$ for the $\mathrm{Br}^{*}$ channel and $2.47 \mathrm{eV}$ for the $\mathrm{Br}$ one. In contrast, the excess energy for the production of $\mathrm{CH}_{3}(v=0)$ $+\mathrm{Br}^{*}$ is $2.385 \mathrm{eV}$. In this region of the image, each pixel corresponds to about $30 \mathrm{meV}$ of translational energy. Images recorded at the peak of the $1_{1}^{1} Q$-branch [Fig. 1(f)] show no significant difference compared with those recorded in the $0_{0}^{0}$ $Q$-branch. We also tried to probe the $\nu_{1}$ vibration through the $1_{1}^{0}$ line, without success. Therefore we conclude that the dissociation dynamics do not significantly involve the symmetric stretching mode in $\mathrm{CH}_{3} \mathrm{Br}$, in contrast to the photodissociation of $\mathrm{CH}_{3} \mathrm{I}$ in which as much as $10 \%$ of the internal energy is channeled into the $\nu_{1}$ mode, albeit only for the ground spin-orbit channel. ${ }^{23,28,29}$

This statement seems consistent with the reported absence of $\nu_{1}$ activity in experiments in the range of 212.8-235 $\mathrm{nm}$ detected by slicing at a velocity resolution three times higher than ours. ${ }^{19}$ With this high-resolution slicing, Janssen et al. ${ }^{19}$ were able to detect fragments excited in the $\nu_{4}$ rocking mode for $\mathrm{CD}_{3} \mathrm{Br}$. It is, however, important to remember that this same slicing experiment shows a strong effect of the D-isotope substitution enhancing production of vibrationally excited methyl in contrast to the lighter isotope, $\mathrm{CH}_{3} \mathrm{Br}$. ${ }^{19}$

The absence of $\nu_{1}$ activity in $\mathrm{CH}_{3} \mathrm{Br}$ dissociation is a somewhat different than $\mathrm{CH}_{3} \mathrm{I}$ photodissociation, where the stretching activity observed mainly for the I channel is associated with impulsive behavior of the photodissociation along the ${ }^{1} Q_{1}$ surface at high available energy. This impulsive feature is expected to be stronger in $\mathrm{CH}_{3} \mathrm{Br}$ since the ${ }^{1} Q_{1}$ surface is steeper than in $\mathrm{CH}_{3} \mathrm{I} .{ }^{14}$ However, none of the investigations on $\mathrm{CH}_{3} \mathrm{Br}$ or $\mathrm{CH}_{3} \mathrm{Cl}$ photodissociation has reported a $\nu_{1}$ activity. Trajectory studies involving potential energy surfaces that take into account this coordinate might be helpful in explaining this difference observed in the $\nu_{1}$ activity of the methyl halides.

\section{Energy distributions and correlation of $\mathrm{CH}_{3} \nu_{2}$ excitation with $\mathrm{Br}$ spin orbit state}

Figure 2 shows the kinetic energy probability distributions obtained from analysis of the images of Fig. 1. This experiment yields the kinetic energy of the $\mathrm{CH}_{3}$ fragments as a function of their umbrella excitation as well as the $\mathrm{Br}$ and $\mathrm{Br}^{*}$ energy distributions. This energy mapping of the fragments allows a more detailed study of the nonadiabatic coupling. In each translational energy distribution for $\mathrm{CH}_{3}(v)$, the lower kinetic energy peak corresponds to production of $\mathrm{Br}^{*}+\mathrm{CH}_{3}(v, J)$ while the higher energy one results from $\mathrm{Br}$ $+\mathrm{CH}_{3}(v, J)$. We fitted each peak with a Lorentzian function. From the derived width parameters (shown in Table I) one can see the $\mathrm{CH}_{3}$ fragments' translational energy distribution is at least $\sim 30 \%$ wider when formed with $\mathrm{Br}$ atoms in comparison to those formed with $\mathrm{Br}^{*}$. This broadening can be explained by a higher degree of rotational excitation of the methyl fragment in the more energetic Br-forming channel, similar to the results in Ref. 19.

We calculated the $\left[\mathrm{Br}^{*}\right] /[\mathrm{Br}]$ branching ratio for each vibrationally state specific channel and found that it decreases as the excitation of the $\mathrm{CH}_{3}$ umbrella mode increases. The decreasing $\left[\mathrm{Br}^{*}\right] /[\mathrm{Br}]$ ratio seen here is in agreement with the propensity previously inferred from $\mathrm{Br}$ atom images by Gougousi et al..$^{5}$ and Underwood et al. ${ }^{20}$

Under the apparently valid assumption that only $\mathrm{CH}_{3}$ umbrella motion is excited, the sum of individual methyl 


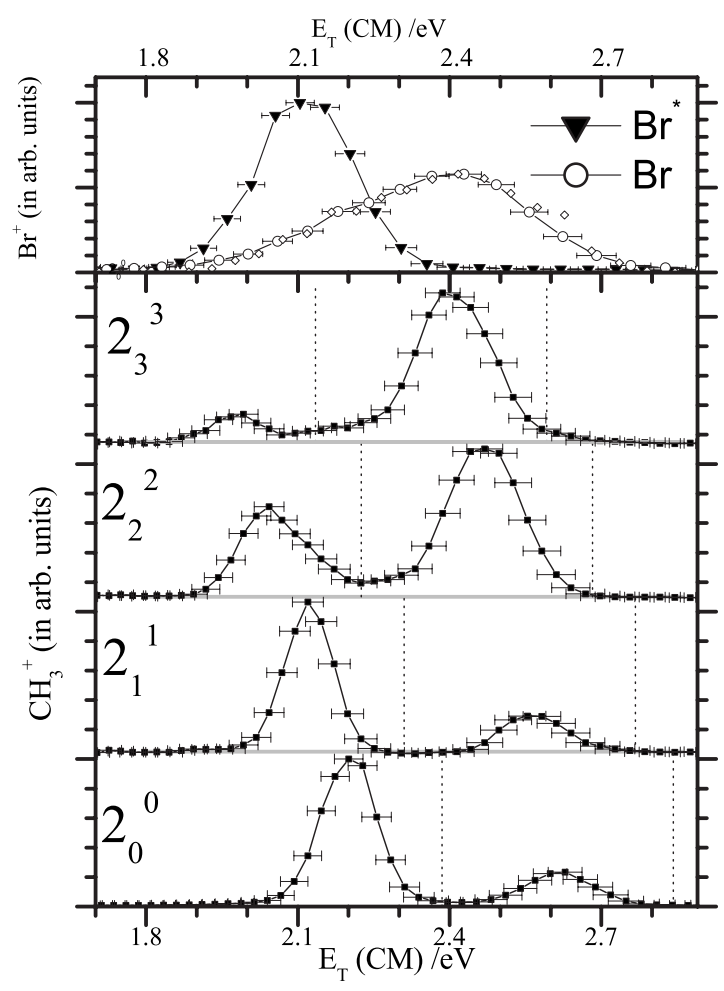

FIG. 2. Kinetic energy release distributions. The top panel is obtained from bromine fragment images. The others are obtained from specific vibrational states of the methyl fragment detected via the $\left(3 p^{2} A_{2}^{\prime \prime}, 2_{v}^{v}\right)$ state. The vertical dotted lines indicate the expected maximum kinetic energy release in the methyl fragments if no methyl rotation were excited. $\operatorname{Br}\left({ }^{2} P_{3 / 2}\right)$ results have been derived from images recorded at two repeller voltages: $3 \mathrm{kV}$ (diamonds) and $5 \mathrm{kV}$ (circles).

distributions should reflect closely the bromine fragment distributions. Consequently, we independently fitted the translational energy distributions of the $\operatorname{Br}\left({ }^{2} P_{3 / 2}\right)$ and $\operatorname{Br}^{*}\left({ }^{2} P_{1 / 2}\right)$ fragments, using the component vibrational state specific translational energy distributions of the $\mathrm{CH}_{3}$ fragments and varying the relative contribution of each $\mathrm{CH}_{3}$ vibrational state.

The vibrational distributions obtained in this way are listed in the last two columns of Table I and the fits to the $\mathrm{Br}$ and $\mathrm{Br}^{*}$ distributions are displayed on Fig. 3. Here, the vibrational distribution of the $\mathrm{Br}^{*}$ channel peaks at $v_{2}=1$ and contributions from vibrational state $v_{2}=2$ and lower are enough to fully reconstruct the distribution. For the $\mathrm{Br}$ channel, it is evident that contributions from the first three quanta in the umbrella mode (observed directly in this work) are not enough to reproduce the translational energy distribution; larger $\mathrm{CH}_{3}$ internal energy is clearly required. We were able to fit the $\mathrm{Br}$ translational distribution with reasonable assumptions about the vibrational state specific $\mathrm{CH}_{3}$ translational energy distributions for higher values of $v_{2}$. For contributions from $v_{2}=4,5$, and 6 , we assume the same rotational energy distribution as that implied by the translational energy distribution for $v_{2}=3$ and used the known vibrational energies of these states. ${ }^{30}$ It remained then only to vary the contributions from each vibrational state to arrive at the good fit shown in Fig. 3(b).

The vibrational excitation is obviously substantially hotter for the $\mathrm{Br}$ channel than for the $\mathrm{Br}^{*}$ channel with a maxi-

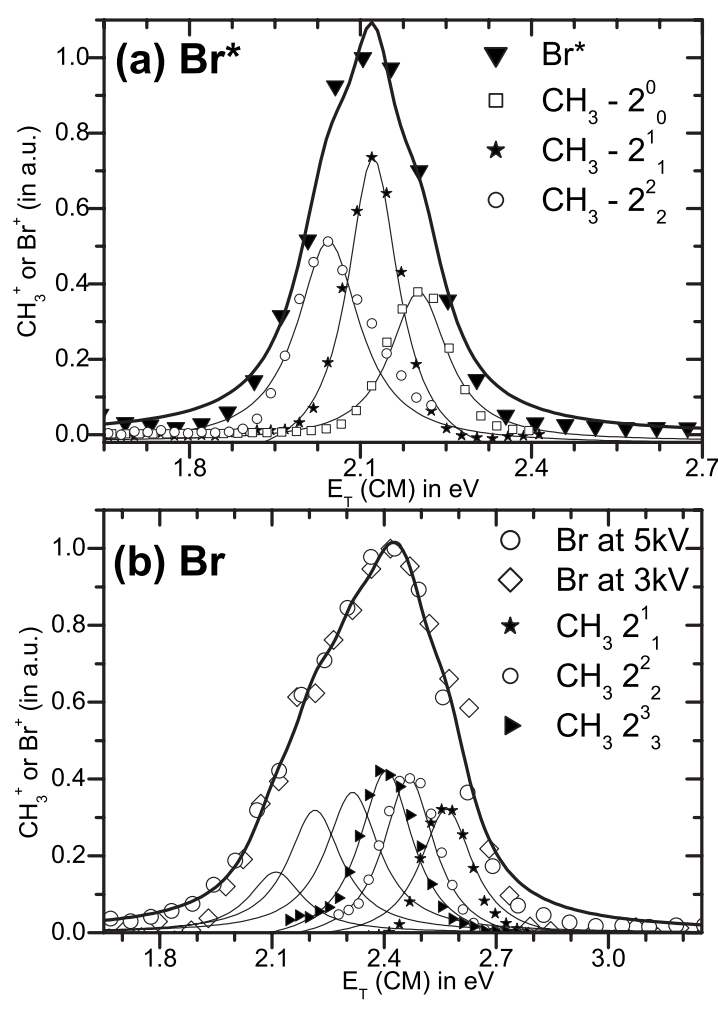

FIG. 3. Reconstruction of Br translational energy distributions from vibrationally state specific translational energy distributions of $\mathrm{CH}_{3}$. (a) $\operatorname{Br}^{*}\left({ }^{2} P_{1 / 2}\right)$ channel and (b) $\operatorname{Br}\left({ }^{2} P_{3 / 2}\right)$ channel. See text. Diamonds correspond to images recorded at $3 \mathrm{kV}$ for the repeller plate and crossed circle at $5 \mathrm{kV}$.

mum near $3 v_{2}$. This confirms the "inverted" distribution previously suggested by Gougousi et al. ${ }^{5}$ and Van Veen et al. ${ }^{13}$ obtained by less direct means. The combination of direct detection of individual quantum states of $\mathrm{CH}_{3}$ as well as $\mathrm{Br}$ and $\mathrm{Br}^{*}$ in this work provides the most reliable and accurate information on the $\mathrm{CH}_{3}$ excitation in $\mathrm{CH}_{3} \mathrm{Br}$ photodissociation and how it varies between the two spin orbit states.

\section{The $\mathrm{Br} / \mathrm{Br}^{*}$ branching ratio}

The $\mathrm{Br}$ and $\mathrm{Br}^{*}$ photofragment quantum yields are related to the $\left[\mathrm{Br}^{*}\right] /[\mathrm{Br}]$ branching ratio by the following equations:

$$
\Phi_{\mathrm{Br}}=\frac{[\mathrm{Br}]}{[\mathrm{Br}]+\left[\mathrm{Br}^{*}\right]}=\frac{1}{1+\frac{\left[\mathrm{Br}^{*}\right]}{[\mathrm{Br}]}} \text { and } \Phi_{\mathrm{Br}^{*}}=1-\Phi_{\mathrm{Br}} \text {. }
$$

Since the two-photon transition strength is not known for the $\mathrm{Br}$ and $\mathrm{Br}^{*}$ REMPI detection scheme we used, it is not possible to evaluate the overall branching ratio $\left[\mathrm{Br}^{*}\right] /[\mathrm{Br}]$ simply by dividing the areas under the $\mathrm{Br}$ and $\mathrm{Br}^{*}$ fragment translational energy distributions in Fig. 2. However $\Phi_{\mathrm{Br}^{*}}$ has been measured by Gougousi et al. ${ }^{5}$ down to $218 \mathrm{~nm}$. Extrapolating those results, we find $\Phi_{\mathrm{Br}^{*}}=0.58 \pm 0.05$ at 215.9 $\mathrm{nm}$. This leads to a branching ratio of $\left[\mathrm{Br}^{*}\right] /[\mathrm{Br}]$ $=1.38 \pm 0.15$ and to $\Phi_{\mathrm{Br}}=0.42 \pm 0.05$.

The $\left[\mathrm{Br}^{*}\right] /[\mathrm{Br}]$ ratio could depend on the $\mathrm{CH}_{3}$ rotation and vibration. We measured images probing through the $0_{0}^{0}$ 
TABLE II. Measured anisotropy parameter $\beta$ shown in Fig. 4 and coefficients for direct and nonadiabatic dissociation for both channels. See text.

\begin{tabular}{|c|c|c|c|c|c|c|c|}
\hline \multirow[b]{2}{*}{ Fragment } & \multirow[b]{2}{*}{$\begin{array}{c}\mathrm{Br} \\
\sum v\end{array}$} & \multicolumn{6}{|c|}{$\mathrm{CH}_{3}$ for different $\nu_{2}$} \\
\hline & & $\begin{array}{c}0 \\
(1+1) \\
\text { REMPI }\end{array}$ & $\begin{array}{c}0-\mathrm{P}(4) \\
(2+1) \\
\text { REMPI }\end{array}$ & $\begin{array}{c}0 \\
(2+1) \\
\text { REMPI }\end{array}$ & $\begin{array}{c}1 \\
(2+1) \\
\text { REMPI }\end{array}$ & $\begin{array}{c}2 \\
(2+1) \\
\text { REMPI }\end{array}$ & $\begin{array}{c}3 \\
(2+1) \\
\text { REMPI }\end{array}$ \\
\hline $\begin{array}{l}\beta \text { for } \\
\text { Br channel }\end{array}$ & $\begin{array}{c}-0.11 \pm 0.01 \\
(-0.11 \pm 0.02 \text { from Ref. } 5)\end{array}$ & $\begin{array}{l}-0.43 \\
\pm 0.02\end{array}$ & $\begin{array}{l}-0.22 \\
\pm 0.02\end{array}$ & $\begin{array}{l}-0.096 \\
\pm 0.012\end{array}$ & $\begin{array}{l}-0.52 \\
\pm 0.02\end{array}$ & $\begin{array}{l}-0.59 \\
\pm 0.03\end{array}$ & $\begin{array}{l}-0.62 \\
\pm 0.03\end{array}$ \\
\hline $\begin{array}{l}\beta \text { for } \\
\mathrm{Br}^{*} \\
\text { channel }\end{array}$ & $\begin{array}{c}1.88 \pm 0.06 \\
(1.86 \pm 0.15 \text { from Ref. } 5)\end{array}$ & $\begin{array}{r}1.35 \\
\pm 0.03\end{array}$ & $\begin{array}{r}1.35 \\
\pm 0.04\end{array}$ & $\begin{array}{r}1.82 \\
\pm 0.04\end{array}$ & $\begin{array}{r}1.54 \\
\pm 0.03\end{array}$ & $\begin{array}{r}1.74 \\
\pm 0.09\end{array}$ & $\begin{array}{r}1.62 \\
\pm 0.12\end{array}$ \\
\hline \multicolumn{4}{|c|}{$\mathrm{Br}$} & \multicolumn{4}{|c|}{$\mathrm{Br}^{*}$} \\
\hline$a_{\text {indirect }}{ }^{3} Q_{0} \rightarrow{ }^{X} Q_{1}$ & $a_{\text {direct }}{ }^{X} Q_{1}$ & $P\left({ }^{X} Q_{1}\right)$ & $P_{01}{ }^{3} Q_{0} \rightarrow{ }^{X} Q_{1}$ & $b_{\text {direct }}{ }^{3} Q_{0}$ & $b_{\text {indirect }}{ }^{X} Q_{1} \rightarrow{ }^{3} Q_{0}$ & $P\left({ }^{3} Q_{0}\right)$ & $P_{10}{ }^{X} Q_{1} \rightarrow{ }^{3} Q_{0}$ \\
\hline $\begin{array}{r}0.296 \\
\pm 0.004\end{array}$ & $\begin{array}{r}0.703 \\
\pm 0.004\end{array}$ & $\begin{array}{r}0.32 \\
\pm 0.05\end{array}$ & $\begin{array}{r}0.18 \\
\pm 0.04\end{array}$ & $\begin{array}{r}0.96 \\
\pm 0.02\end{array}$ & $\begin{array}{r}0.04 \\
\pm 0.02\end{array}$ & $\begin{array}{r}0.68 \\
\pm 0.07\end{array}$ & $\begin{array}{r}0.07 \\
\pm 0.05\end{array}$ \\
\hline
\end{tabular}

$Q$-branch, which show an increase in the $\left[\mathrm{Br}^{*}\right] /[\mathrm{Br}]$ ratio as one tunes from the blue to the red. This effect has been previously observed ${ }^{26}$ and studied in $\mathrm{CH}_{3} \mathrm{I} .{ }^{31}$ The bending mode of the parent molecule is not only the promoting mode for the nonadiabatic coupling between ${ }^{1} Q_{1}$ and ${ }^{3} Q_{0}$, but also correlated with rotation of $\mathrm{CH}_{3}$ fragments. For example, for trajectories that explore bent geometries near the ${ }^{1} Q_{1^{-}}{ }^{3} Q_{0}$ curve crossing, larger rotational excitation of the methyl fragment is expected for the ${ }^{1} Q_{1}$ than for the ${ }^{3} Q_{0}$ state. ${ }^{16}$ Note that from the ratio $\left[\mathrm{Br}^{*}\right] /[\mathrm{Br}]$ in the detection of $\mathrm{CH}_{3}$ produced in the origin band (see Table II), we can compare the yield $\Phi_{\mathrm{Br}^{*}}=0.82 \pm 0.04$ measured at $215.9 \mathrm{~nm}$ in our case on a supersonic molecular beam to $\Phi_{\mathrm{Br}^{*}}=0.72$ measured at $213 \mathrm{~nm}$ by selecting the initial parent molecule $(K=J=1)$ of Lipciuc and Janssen. ${ }^{19}$ These two ratios are in good agreement.

\section{Angular distributions and alignment in $\mathrm{CH}_{3}$}

The angular distributions $I(\theta)$ of the photofragments were obtained by integrating the Abel-inverted images over the radial full-width half maximum of each of the peaks shown in Fig. 2. The angular distributions were fitted to the expression

$$
I(\theta) \propto 1+\frac{\beta}{2}\left(3 \cos ^{2} \theta-1\right),
$$

where $\beta$ is the photofragment recoil anisotropy parameter for a given dissociation channel. The distributions and fits are presented in Fig. 4 and the values for the anisotropy parameters shown in the first two rows of Table II. Looking at the symmetry of the states involved, one would expect, in the limit of a prompt dissociation, that $\mathrm{Br}$ and $\mathrm{CH}_{3}$ produced by excitation to ${ }^{1} Q_{1}$ and ${ }^{3} Q_{1}$ states to have a perpendicular transition character and $\beta=-1$, while $\mathrm{Br}^{*}$ and $\mathrm{CH}_{3}$ produced by excitation to the ${ }^{3} Q_{0}$ state to exhibit a parallel transition character and $\beta=+2$.

The $\beta$ parameters derived from bromine fragment angular distributions are 1.88 for the $\mathrm{Br}^{*}$ producing channel and -0.11 for the $\mathrm{Br}$ channel, in good agreement with previous results. ${ }^{5}$ The $\mathrm{Br}^{*}$ channel's anisotropy agrees approximately with the parallel transition picture of ${ }^{3} Q_{0}$ excitation of $\mathrm{CH}_{3} \mathrm{Br}$. The Br channel's almost isotropic angular distribution is, however, inconsistent with a perpendicular transition for $\mathrm{CH}_{3} \mathrm{Br}$ excitation to ${ }^{3} Q_{1} /{ }^{1} Q_{1}$ states. This can be explained ${ }^{5}$ by the nonadiabatic coupling between the ${ }^{3} Q_{0}$ to the ${ }^{1} Q_{1}$ state, which gives parallel character to the otherwise perpendicular transitions. The observed $\beta$ parameters can be rewritten as a combination of direct and indirect contributions as follows:

$$
\begin{aligned}
& \beta(\mathrm{Br})=a_{\text {indirect }} \beta\left({ }^{3} Q_{0}\right)+a_{\text {direct }} \beta\left({ }^{X} Q_{1}\right), \\
& a_{\text {indirect }}+a_{\text {direct }}=1, \\
& \beta\left(\mathrm{Br}^{*}\right)=b_{\text {direct }} \beta\left({ }^{3} Q_{0}\right)+b_{\text {indirect }} \beta\left({ }^{X} Q_{1}\right), \\
& b_{\text {indirect }}+b_{\text {direct }}=1 .
\end{aligned}
$$

Here the coefficient $a_{\text {direct }}$ is the quantum yield for direct excitation to the ${ }^{X} Q_{1}$ states and dissociation yielding $\operatorname{Br}\left({ }^{2} P_{3 / 2}\right)$ atoms. The $a_{\text {indirect }}$ coefficient is the probability for excitation to the ${ }^{3} Q_{0}$ state followed by nonadiabatic transition and dissociation along the ${ }^{X} Q_{1}$ state(s) to form $\operatorname{Br}\left({ }^{2} P_{3 / 2}\right)$ atoms. $b$ 's are defined in an analogous fashion. The four coefficients of Eq. (3) can be calculated taking the approximation of a pseudodiatomic system with a dissociation time occurring on a faster timescale than the rotational period of the parent molecule, so that $\beta\left({ }^{3} Q_{0}\right)$ and $\beta\left({ }^{X} Q_{1}\right)$ have the values of a perfect parallel and perpendicular transition respectively, namely $\beta\left({ }^{3} Q_{0}\right)=2$ and $\beta\left({ }^{X} Q_{1}\right)=-1$. The coefficients for $\mathrm{Br}$ fragments (Table II) show that $a_{\text {indirect }}=0.3$ of the $\mathrm{Br}$ fragments come from ${ }^{3} Q_{0} \rightarrow{ }^{X} Q_{1}$ nonadiabatic coupling in agreement with results published by Gougousi et al. ${ }^{5}$ If the same procedure is applied to the $\mathrm{Br}^{*}$ channel, we find that almost all $\left(b_{\text {direct }}=0.96\right) \mathrm{Br}^{*}$ is produced by a direct pathway. The excitation probability to different surfaces $\left({ }^{3}{ }^{3} Q_{0}\right.$ and $\left.P_{X_{Q_{1}}}\right)$ and the coupling between these surfaces $\left(P_{10}\right.$ and $\left.P_{01}\right)$ can be calculated from the quantum yields $\Phi_{\mathrm{Br}^{*}}$ $=0.58 \pm 0.05$ and $\Phi_{\mathrm{Br}}=0.42 \pm 0.05$ (Ref. 5) and $a$ and $b$ coefficients as follows and the results are summarized in Table II: 

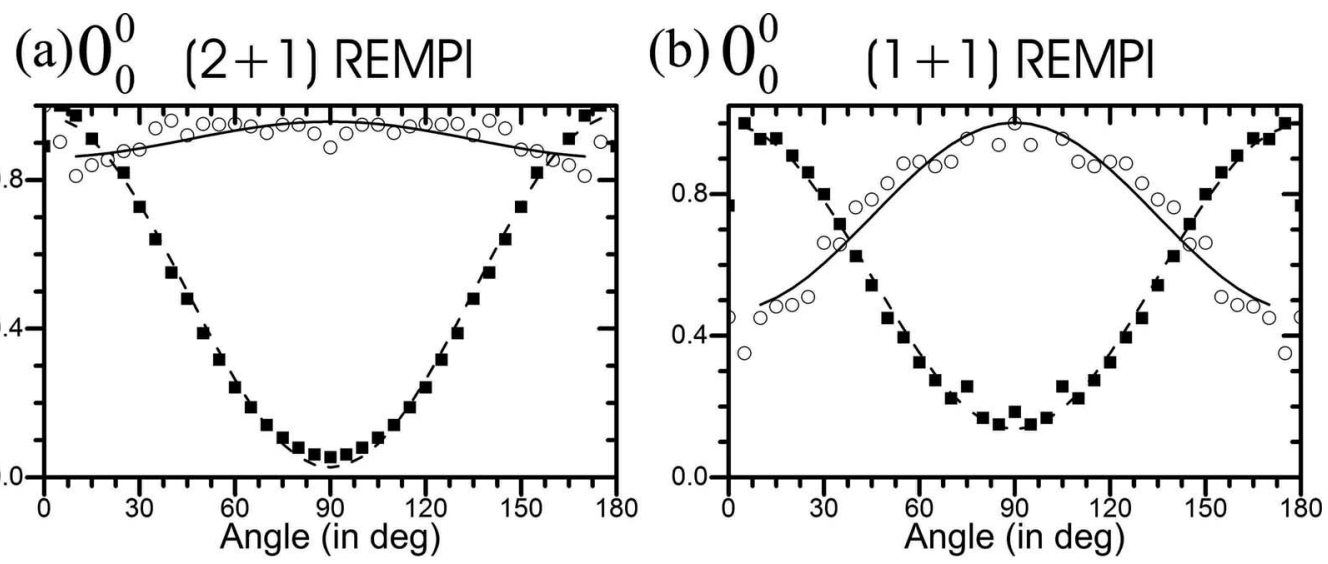

(c) $2_{1}^{1}$

(d) $2_{2}^{2}$
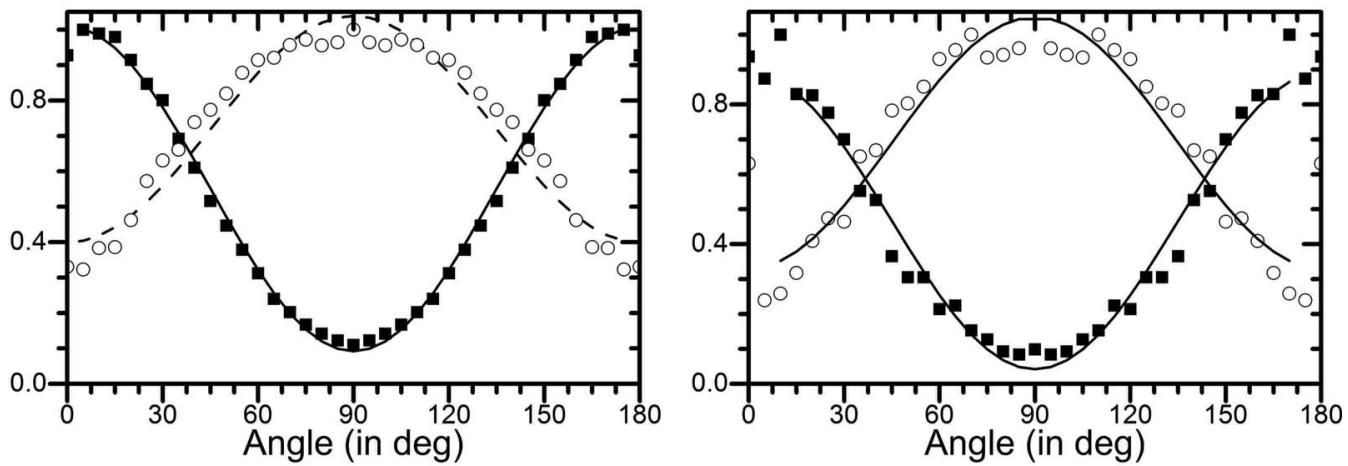

(e) $2_{3}^{3}$

(f) $\mathrm{Br}$ and $\mathrm{Br}^{*}$
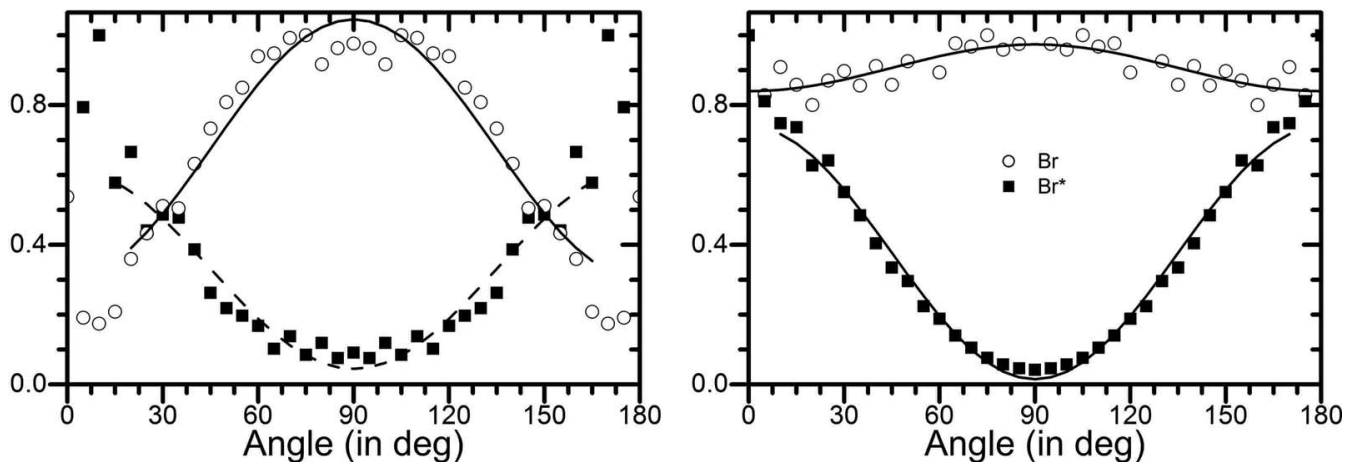

FIG. 4. Angular distributions of bromine atom and methyl fragment calculated from the images shown in Fig. 1. In each panel the circles correspond to the distribution for the $\mathrm{Br}$ channel and the squares correspond to the $\mathrm{Br}^{*}$ channel. The solid lines correspond to the fit using Eq. (2) with the anisotropy parameters listed in the Table II.

$$
\begin{aligned}
& P_{01}=P^{3} Q_{0} \rightarrow{ }^{X} Q_{1}=\frac{a_{\text {indirect }} \Phi_{\mathrm{Br}}}{a_{\text {indirect }} \Phi_{\mathrm{Br}}+b_{\mathrm{D}} \Phi_{\mathrm{Br}^{*}}}, \\
& { }^{{ }^{3} Q_{0}}=a_{\text {indirect }} \Phi_{\mathrm{Br}}+b_{\mathrm{D}} \Phi_{\mathrm{Br}},
\end{aligned}
$$

and

$$
\begin{aligned}
& P_{10}=P^{x_{Q_{1} \rightarrow{ }^{3} Q_{0}}}=\frac{b_{\text {indirect }} \Phi_{\mathrm{Br}^{*}}}{b_{\text {indirect }} \Phi_{\mathrm{Br}^{*}}+a_{\mathrm{D}} \Phi_{\mathrm{Br}}}, \\
& P^{x_{Q_{1}}}=b_{\text {indirect }} \Phi_{\mathrm{Br}^{*}}+a_{\mathrm{D}} \Phi_{\mathrm{Br}} .
\end{aligned}
$$

Conservation of momentum dictates that the state specific angular distributions of the $\mathrm{CH}_{3}$ fragments, weighted by the $\mathrm{CH}_{3}$ quantum state population distribution, match those of the $\mathrm{Br}$ fragments. It is evident from the values in Table II that this is not the case. We attribute these differences to alignment of the methyl fragment, which appears to be particularly important for vibrationally excited $\mathrm{CH}_{3}$, as well as the influence of vibrationally enhanced predissociation in the REMPI detection used here.

Rotational alignment has been observed before for methyl following photodissociation of $\mathrm{CH}_{3} \mathrm{I}$. Powis and co-worker ${ }^{28,32}$ found that $\mathrm{CD}_{3}$ produced by dissociation of 
TABLE III. Angular distribution fits to an expansion of Legendre polynomials: due to more rapid predissociation for higher vibrational states, higher vibrational levels have less intensity and greater experimental uncertainty.

\begin{tabular}{lcccc}
\hline \hline Mass & State & $\beta_{2}$ & $\beta_{4}$ & $\beta_{6}$ \\
\hline $\mathrm{CH}_{3} \mathrm{Br}^{*}$ & $0_{0}^{0}(Q)$ & $1.79 \pm 0.01$ & $0.16 \pm 0.01$ & $-0.02 \pm 0.01$ \\
& $0_{0}^{0} P(4)+1_{1}^{1}$ & $1.32 \pm 0.03$ & $0.19 \pm 0.03$ & $0.09 \pm 0.03$ \\
& $2_{1}^{1}$ & $1.26 \pm 0.05$ & $0.29 \pm 0.05$ & $0.03 \pm 0.07$ \\
& $2_{2}^{2}$ & $1.28 \pm 0.08$ & $0.20 \pm 0.08$ & $0.09 \pm 0.1$ \\
& $2_{3}^{3}$ & $1.57 \pm 0.12$ & $0.36 \pm 0.10$ & $-0.20 \pm 0.13$ \\
$\mathrm{Br}$ & ${ }^{2} P_{3 / 2}$ & $-0.11 \pm 0.01$ & $0.02 \pm 0.02$ & $0.005 \pm 0.02$ \\
$\mathrm{CH} H_{3} \mathrm{Br}$ & $0_{0}^{0} P(4)+1_{1}^{1}$ & $0.42 \pm 0.08$ & $0.18 \pm 0.1$ & $0.01 \pm 0.1$ \\
& $0_{0}^{0}(Q)$ & $-0.03 \pm 0.01$ & $-0.08 \pm 0.01$ & $-0.03 \pm 0.01$ \\
& $2_{1}^{1}$ & $-0.55 \pm 0.05$ & $0.08 \pm 0.04$ & $-0.12 \pm 0.04$ \\
& $2_{2}^{2}$ & $-0.54 \pm 0.01$ & $-0.09 \pm 0.01$ & $0.02 \pm 0.03$ \\
& $2_{3}^{3}$ & $-0.62 \pm 0.02$ & $-0.22 \pm 0.02$ & $0.03 \pm 0.03$ \\
\hline \hline
\end{tabular}

$\mathrm{CD}_{3} \mathrm{I}$ at $266 \mathrm{~nm}$ is strongly aligned, rotating mainly around its $C_{3}$ axis with $K= \pm N$, where $N$ is the total angular momentum excluding spin and $K$ its projection along its threefold symmetry axis. However this alignment probably originates from rotationally hot parent molecules present in the $300 \mathrm{~K}$ effusive molecular beam used in that work. Ogorzalek Loo et al. ${ }^{26}$ used a supersonic molecular beam and their experimental results on both $\mathrm{CD}_{3} \mathrm{I}$ and $\mathrm{CH}_{3} \mathrm{I}$ conclude that $\mathrm{CD}_{3}$ and $\mathrm{CH}_{3}$ fragments are also aligned; however, here $K=0$ dominates reflecting rotation around an axis perpendicular to the threefold symmetry axis. These results were confirmed by Janssen et $a .^{33}$ who, following the treatment of Kummel and Zare, ${ }^{34}$ measured the alignment parameters from O, P, R, and $\mathrm{S}$ branch methyl spectra in $\mathrm{CD}_{3} \mathrm{I}$. In the current case we do not have enough polarization geometries and wavelengths to address this problem quantitatively.

Still we can take an approach, which is at least sufficient to demonstrate that alignment effects are present. In an approximate fashion, we fitted our experimental angular distribution to a series expansion of even Legendre polynomials ${ }^{35}$ terminated at the sixth order polynomial

$$
I(\theta)=1+\beta_{2} P_{2}(\cos \theta)+\beta_{4} P_{4}(\cos \theta)+\beta_{6} P_{6}(\cos \theta) .
$$

In this expansion, alignment will manifest itself with nonzero values for $\beta_{4}$ and/or $\beta_{6}$.

The results of this fitting procedure are presented in Table III and the fits to the data are presented in Fig. 4. Values of $\beta_{6}$ are-within our experimental error-zero. However, $\beta_{4}$ clearly exhibits nonzero values for most vibrational quanta and are generally higher in $\mathrm{CH}_{3}+\mathrm{Br}^{*}$ than in $\mathrm{CH}_{3}+\mathrm{Br}$ channel. This result shows the presence of $\mathrm{CH}_{3}$ alignment in both channels and that $\mathrm{CH}_{3}$ alignment is more important in the $\mathrm{CH}_{3}+\mathrm{Br}^{*}$ channel, although the rotational temperature seems to be lower in that channel. It is likely that the stronger alignment in the $\mathrm{CH}_{3}+\mathrm{Br}^{*}$ channel is related to its direct dissociation mechanism.

Fitting $\mathrm{Br}$ and $\mathrm{Br}^{*}$ angular distributions in the same fashion does not indicate significant alignment of $\mathrm{Br}$. Note also that $\operatorname{Br}\left({ }^{2} P_{1 / 2}\right)$ with $J=1 / 2$ cannot have alignment.

The presence of alignment as well as the predissociation of the $\mathrm{CH}_{3} 3 p$ intermediate Rydberg state ${ }^{28,32}$ prevent us from using methyl angular distributions to extract curve

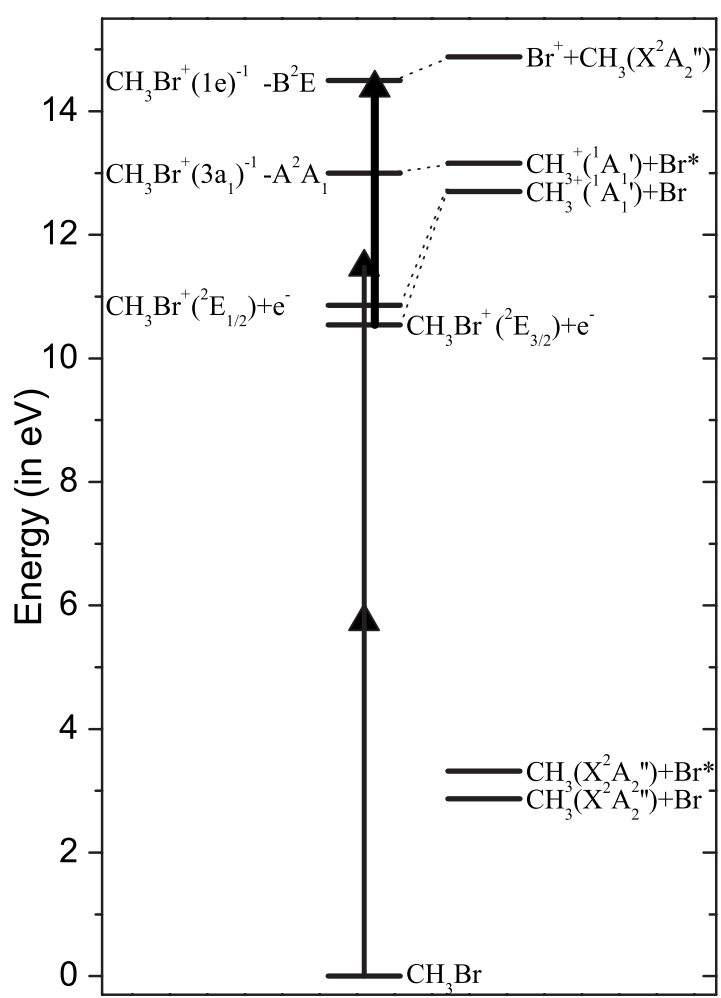

FIG. 5. Energy diagram of the photodissociation of methyl bromide cation in $C_{3 v}$ geometry with adiabatic correlation to products shown by dotted lines.

crossing probabilities as a function of methyl fragment excitation. However, it is noteworthy that the methyl angular distributions vary only weakly with vibrational excitation (see Table III) indicating that the curve crossing probability will not change significantly. This is consistent with the analysis of Underwood et al. ${ }^{20}$

\section{B. Methyl bromide cation}

\section{Identification of ion dissociation}

In order to determine the origin of the low velocity rings in the $\mathrm{CH}_{3}{ }^{+}$images we have also obtained ion images at $m / z=94-96\left(\mathrm{CH}_{3} \mathrm{Br}^{+}\right)$. These images (not shown) appear as tiny dots at the velocity origin, as expected for ionized $\mathrm{CH}_{3} \mathrm{Br}$ traveling with the velocity of the molecular beam. When the laser light used for $\mathrm{CH}_{3}$ REMPI detection (hereafter referred to as "the ion-dissociation laser") is introduced at wavelengths near $330 \mathrm{~nm}$, we observe that the $\mathrm{CH}_{3} \mathrm{Br}^{+}$peak is reduced by as much as $\sim 75 \%$ without any significant change in the intensity of ${ }^{79,81} \mathrm{Br}^{+}$. This clearly shows the occurrence of the following channel: ${ }^{36}$

$$
\begin{aligned}
& \mathrm{CH}_{3} \mathrm{Br}+2 h \nu_{\lambda=215.9 \mathrm{~nm}} \rightarrow \mathrm{CH}_{3} \mathrm{Br}^{+}+e^{-}, \\
& \mathrm{CH}_{3} \mathrm{Br}^{+}+h \nu_{\lambda=322-334 \mathrm{~nm} \text { ("ion-dissociation laser”) }} \\
& \rightarrow \mathrm{CH}_{3}^{+}+\mathrm{Br} / \mathrm{Br}^{*} .
\end{aligned}
$$

Fig. 5 for an energy diagram. The additional smaller-radius rings in the $\mathrm{CH}_{3}{ }^{+}$images [Figs. 1(c)-1(f)] correspond to this second source of $\mathrm{CH}_{3}{ }^{+}$.

The ground electronic state $\left({ }^{2} E_{3 / 2}\right)$ of $\mathrm{CH}_{3} \mathrm{Br}^{+}$is formed by the removal of a nonbonding $(2 e)$ electron from one of 
the halogen lone pairs. This state's geometry is similar to the neutral ground state but with a slight elongation of the $\mathrm{C}-\mathrm{Br}$ bond $^{37}$ as well as a Jahn-Teller distortion from $C_{3 v}$ geometry. ${ }^{2}$ The ionization energy to form $\mathrm{CH}_{3} \mathrm{Br}^{+}\left(X^{2} E_{3 / 2}\right)$ is $10.54 \mathrm{eV}$ (Refs. 38 and 39) and the spin orbit excited $X^{2} E_{1 / 2}$ state lies at $10.86 \mathrm{eV}^{40}$ Two photons at $215.9 \mathrm{~nm}$ $(11.48 \mathrm{eV})$ are sufficient to reach the ionization continuum but not enough to reach dissociative ionization threshold $(12.74 \mathrm{eV})$ leading to $\mathrm{CH}_{3}{ }^{+}\left({ }^{1} A_{1}\right)+\mathrm{Br}\left({ }^{2} P_{3 / 2}\right) \cdot{ }^{39,41}$ Although it has never been observed, ${ }^{42}$ the appearance potential of $\mathrm{CH}_{3}{ }^{+}\left({ }^{1} A_{1}\right)+\operatorname{Br}\left({ }^{2} P_{1 / 2}\right)$ is expected at $13.2 \mathrm{eV}$. One photon from the ion-dissociation laser is required to dissociate $\mathrm{CH}_{3} \mathrm{Br}^{+}$. Photoelectron spectroscopy of $\mathrm{CH}_{3} \mathrm{Br}$ shows that the first electronically excited state of $\mathrm{CH}_{3} \mathrm{Br}^{+}$lies $13 \mathrm{eV}$ above $\mathrm{CH}_{3} \mathrm{Br}$ with a vertical excitation energy of $13.5 \mathrm{eV}$ (Refs. 2, 44, and 45) (see Fig. 5). This state is formed by removing an electron from the $\left(3 a_{1}\right)$ outer-valence molecular orbital associated with the $\mathrm{C}-\mathrm{Br}$ bond and labeled $A^{2} A_{1}$. Excitation to this state yields, with $100 \%$ efficiency, the $\mathrm{CH}_{3}{ }^{+}$fragment. ${ }^{44}$ Some vibrational bands have been observed around $12.8 \mathrm{eV}$ revealing a bound character of the $A^{2} A_{1}$ state at energies lower than those relevant to this work. $^{39}$

\section{The observation of highly vibrationally excited $\mathrm{CH}_{3}{ }^{+}$}

The inner ring structure observed in Figs. 1(c)-1(f) depends only weakly on the wavelength of the ion-dissociation laser. Figure 6 shows the translational energy distributions for $\mathrm{CH}_{3} \mathrm{Br}^{+}$photodissociation derived from each image. In order to compare results at different photolysis wavelengths, the translational energy scale has been shifted relative to the available energy for the experiment carried out with the iondissociation laser at $h \nu_{\mathrm{ref}}=3.84 \mathrm{eV}(322.8 \mathrm{~nm})$, corresponding to the image shown in Fig. 1(e). The energy scale shift was imposed according to the following formulas:

$$
\begin{aligned}
& E_{T}(\nu)=E_{\text {kin }}^{\mathrm{CH}_{3}}(\text { measured }) \times \frac{m_{\mathrm{CH}_{3} \mathrm{Br}}}{m_{\mathrm{Br}}}+\Delta, \\
& \Delta=h\left(\nu_{\text {ref }}-\nu\right),
\end{aligned}
$$

where $\nu$ is the frequency of the ion-dissociation laser. This approach to the analysis allows us to identify vibrational progressions of the $\mathrm{CH}_{3}{ }^{+}$product that appear in different experiments. Using this analysis, we discover a progression of states at center-of-mass translational energies: 33, 190, 376,528 , and $686 \mathrm{meV}$. Observation of this progression is additional evidence demonstrating the multiphoton scheme of Fig. 5.

To assign these quantized features requires additional consideration as one cannot a priori determine which states of the $\mathrm{CH}_{3} \mathrm{Br}^{+}$are formed by the two-photon ionization at $215.9 \mathrm{~nm}$. Inspection of Fig. 6 shows that nearly all of the ion signal appears below $1.5 \mathrm{eV}$. With an ion-dissociation laser photon of $h \nu_{\text {ref }}=3.84 \mathrm{eV}$, one gets an appearance energy for $\mathrm{CH}_{3}{ }^{+}+\mathrm{Br}$ at 12.88 , which is in good agreement with the appearance energy of $12.74 \mathrm{eV}$ expected for the $A$ state

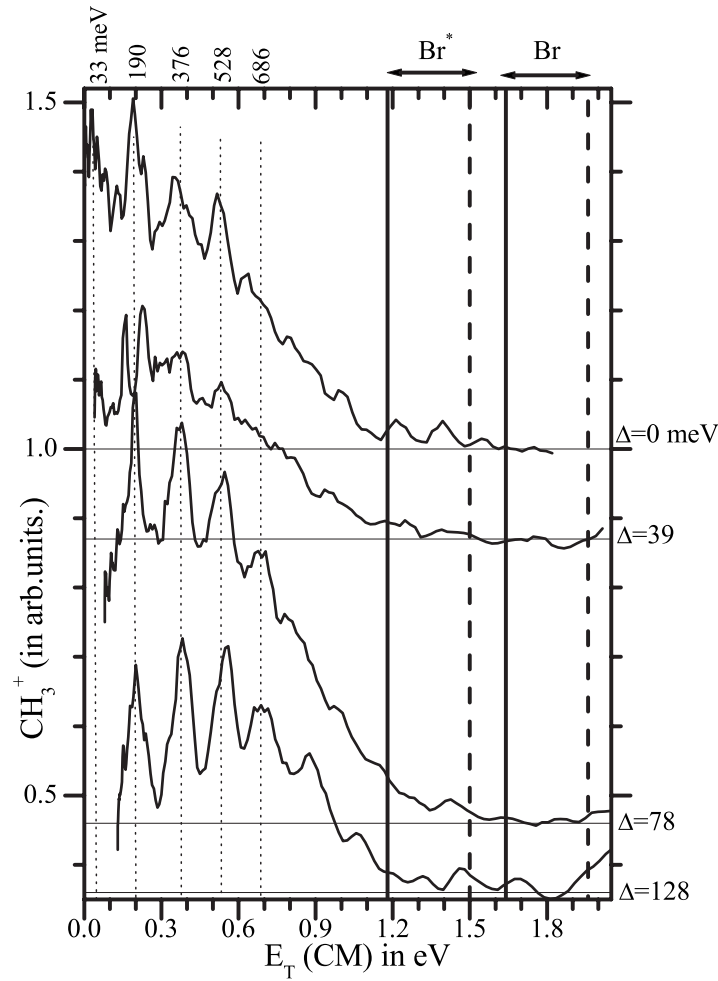

FIG. 6. Vibrational progression in $\mathrm{CH}_{3}{ }^{+}$obtained from central rings in the images of Fig. 1. An energy shift $\triangle$ relative to the photodissociation of $\mathrm{CH}_{3} \mathrm{Br}^{+}$taking place at $322.8 \mathrm{~nm}\left(2_{3}^{3}\right.$ REMPI wavelength) is introduced to account for the change in photolysis wavelength in each image. The maximum available energy for translation is indicated by vertical lines, for photodissociation of $\mathrm{CH}_{3} \mathrm{Br}^{+}$to $\mathrm{CH}_{3}{ }^{+}+\mathrm{Br}$ or $\mathrm{CH}_{3}{ }^{+}+\mathrm{Br}^{*}$ with a cation initial state $X^{2} E_{3 / 2}$ (solid lines) or $X^{2} E_{1 / 2}$ (dashed lines).

$$
\begin{aligned}
& \mathrm{CH}_{3} \mathrm{Br}^{+}\left({ }^{2} E_{3 / 2}\right)+h \nu_{\lambda=322.8 \mathrm{~nm}} \\
& \quad \rightarrow\left(\mathrm{CH}_{3}{ }^{+}+\mathrm{Br}\right)\left(E_{T}=10.54+3.84-12.74 \mathrm{eV}\right. \\
&\quad=1.64 \mathrm{eV}) .
\end{aligned}
$$

We are able to reproduce the progression of Fig. 6 using a vibrational harmonic frequency of $\mathrm{CH}_{3}{ }^{+} \nu_{4}=170 \mathrm{meV}$ (inplane bend) or $\nu_{2}=168 \mathrm{~cm}^{-1}$ (umbrella mode). ${ }^{43}$ Table IV shows this analysis more completely. More generally, it is clear that there is a propensity for channeling available energy into $\mathrm{CH}_{3}{ }^{+}$vibration and not into translation.

TABLE IV. Vibrational progression in $\mathrm{CH}_{3}{ }^{+}$fragment.

\begin{tabular}{ccccc}
\hline $\begin{array}{c}\text { Expt. } \\
\text { data }(\mathrm{meV})^{\mathrm{a}}\end{array}$ & $v^{\mathrm{b}}$ from $E_{3 / 2}$ & $v^{\mathrm{b}}$ from $E_{1 / 2}$ & $\begin{array}{c}\text { Fitted } \\
\text { results }\end{array}$ & Expt. -fit \\
\hline 686 & 3 & 5 & $693 \mathrm{meV}$ & $7 \mathrm{meV}$ \\
528 & 4 & 6 & 527 & 1 \\
376 & 5 & 7 & 362 & 6 \\
190 & 6 & 8 & 197 & 7 \\
33 & 7 & 9 & 34 & 1 \\
\hline \hline
\end{tabular}

${ }^{\mathrm{a}}$ From the peaks in Fig. 6.

${ }^{\mathrm{b}}$ Vibrational quanta in $\nu_{2}$ or $\nu_{4}$. See text.

${ }^{\mathrm{c}}$ Based on the formula $1282-\left[169.9(v+1 / 2)+0.468(v+1 / 2)^{2}\right]$ in meV. The appearance threshold of dissociation is at $1.197 \pm 0.010 \mathrm{eV}$ in good agreement with $\mathrm{CH}_{3} \mathrm{Br}^{+}\left({ }^{2} E_{3 / 2}\right) \rightarrow \mathrm{CH}_{3}{ }^{+}+\mathrm{Br}^{*}\left({ }^{2} P_{1 / 2}\right)$ or based on the formula $1615-\left[169.9(v+1 / 2)+0.350(v+1 / 2)^{2}\right]$ in meV. The appearance threshold of dissociation is at $1.531 \pm 0.013 \mathrm{eV}$ in good agreement with $\mathrm{CH}_{3} \mathrm{Br}^{+}\left({ }^{2} E_{1 / 2}\right) \rightarrow \mathrm{CH}_{3}{ }^{+}+\mathrm{Br}^{*}\left({ }^{2} P_{1 / 2}\right)$. 
Two-photon threshold photoelectron spectra shows that photoionization onto $X^{2} E_{1 / 2}$ dominates. ${ }^{40}$ If $A^{2} A_{1}$ was the dissociating state accessed directly by $\mathrm{CH}_{3} \mathrm{Br}^{+}$absorption of a $330 \mathrm{~nm}$ photon, the angular distribution would be expected to be perpendicular, yet we observe a parallel process. Thus an indirect dissociation process must be important. For example, the second excited electronic state seen in $\mathrm{CH}_{3} \mathrm{Br}$ photoelectron spectroscopy around $14.5 \mathrm{eV}$ possesses $E$ symmetry ( $B$ state in Fig. 5$){ }^{42}$ This state correlates adiabatically to $\mathrm{CH}_{3}\left(X^{2} A_{2}^{\prime \prime}\right)+\mathrm{Br}^{+}\left({ }^{3} P\right)$. It has been shown in the case of $\mathrm{CH}_{3} \mathrm{Cl}$ that a favorable overlap of the orbitals makes the oscillator strength to the B state $\left(\pi^{*} \leftarrow \pi\right)$ much larger than to the A state $(\sigma \leftarrow \pi) .{ }^{47}$ In the same work, a parallel electronic transition has been observed in an energy range similar to that of the $A$ state absorption. ${ }^{47}$ In addition, the coupling between the $B$ and $A$ states of the cation has been proposed to rationalize experimental observations in multiphoton ionization of $\mathrm{CH}_{3} \mathrm{I}^{46}$

It is interesting to compare the kinetic energy release distributions of $\mathrm{CH}_{3}{ }^{+}$observed in Fig. 6 with the ones recorded by one-photon dissociative ionization: ${ }^{42}$ the average translational energy observed in a one photon experiment at $h \nu=14.3 \mathrm{eV}$ (close to the present energy) is $\sim 0.4 \mathrm{eV}^{42}$ which is remarkably similar to the observations of this work.

Thus, internal conversion to the $A^{2} A_{1}$ state would involve electron transfer from $\mathrm{CH}_{3}$ to $\mathrm{Br}$, possibly explaining the large vibrational excitation seen in the $\mathrm{CH}_{3}{ }^{+}$product.

\section{CONCLUSION}

We have measured angular and kinetic energy distributions of state selected methyl and bromine fragments using velocity map imaging of single and multiphoton excitation of $\mathrm{CH}_{3} \mathrm{Br}$ at $215.9 \mathrm{~nm}$. Our single photon data confirm previous results on differences between $\mathrm{Br}$ and $\mathrm{Br}^{*}$ channels for methyl production with $v_{2}$ umbrella mode excitation and show that $\left[\mathrm{Br}^{*}\right] /[\mathrm{Br}]$ branching ratio decreases with umbrella mode excitation. The $v_{2}$-state specific imaging measurements of $\mathrm{CH}_{3}$ photofragments show that $\mathrm{CH}_{3} \mathrm{Br}$ photolysis produces vibrationally hot methyl peaking at $v_{2}=1$ for the $\mathrm{Br}$ channel and at $v_{2}=3$ for the $\mathrm{Br}^{*}$ channel. Although absorption to the $\mathrm{Br}^{*}$ producing ${ }^{3} Q_{0}$ state dominates the $\tilde{A} \leftarrow X$ band at this wavelength, significant amount of $\mathrm{Br}$ product is observed, $18 \%$ of which comes from ${ }^{3} Q_{0} \rightarrow{ }^{X} Q_{1}$ avoided crossing. Alignment effects observed in methyl fragments and predissociation of the intermediate states used for REMPI detection prevented the extraction of nonadiabatic probabilities from methyl data as a function of $v_{2}$. Qualitatively, based on the overall angular distribution behavior with $v_{2}$ excitation there seems to be no significant dependence on the methyl umbrella mode excitation on the curve crossing probability.

In addition to single photon data, a $2+1^{\prime}$ excitation scheme of $\mathrm{CH}_{3} \mathrm{Br}$ is detected in methyl images, where two photons of $215.9 \mathrm{~nm}$ light produce $\mathrm{CH}_{3} \mathrm{Br}^{+}$which subsequently absorbs a photon of $320-330 \mathrm{~nm}$ and is excited via a parallel transition to $E$-symmetry excited ionic state. Coupling of those states to the $A$ excited state of $\mathrm{CH}_{3} \mathrm{Br}^{+}$leads to production of vibrationally hot $\mathrm{CH}_{3}{ }^{+}$(possibly in the $\nu_{4}$ degenerate bending mode excited by the nonadiabatic state mixing) and $\mathrm{Br}^{*}$.

\section{ACKNOWLEDGMENTS}

The authors would like to thank B. Lepetit, S. Pratt, and P. Rakitzis for fruitful discussions. V.B. acknowledges support from the CNRS institution during her stay in UCSB. A.M.W. and P.S. acknowledge the support of the AFOSR under Contract No. FA9550-04-1-0057.

${ }^{1}$ L. T. Molina, M. J. Molina, and F. S. Rowland, J. Phys. Chem. A 86, $2672(1982)$

${ }^{2}$ R. Locht, B. Leyh, H. W. Jochims, and H. Baumgartel, Chem. Phys. 317, 73 (2005).

${ }^{3}$ C. Escure, B. Lepetit, and T. Leininger (private communication).

${ }^{4}$ B. A. Alekseyev, L. Heinz-Peter, and J. B. Robert, J. Chem. Phys. 126, 234103 (2007).

${ }^{5}$ T. Gougousi, P. C. Samartzis, and T. N. Kitsopoulos, J. Chem. Phys. 108, 5742 (1998).

${ }^{6}$ D. Ajitha, M. Wierzbowska, R. Lindh, and P. A. Malmqvist, J. Chem. Phys. 121, 5761 (2004).

${ }^{7}$ W. S. McGivern, A. Derecskei-Kovacs, S. W. North, and J. S. Francisco, J. Phys. Chem. A 104, 436 (2000); S. J. Paddison and E. TschuikowRoux, ibid. 102, 6191 (1998).

${ }^{8}$ W. S. McGivern, R. Li, P. Zou, and S. W. North, J. Chem. Phys. 111, 5771 (1999).

${ }^{9}$ B. Tang, R. Zhu, Y. Tang, L. Ji, and B. Zhang, Chem. Phys. 303, 37 (2004).

${ }^{10}$ B. Zhang, J. Zhang, and K. Liu, J. Chem. Phys. 122, 104310 (2005).

${ }^{11}$ Y. Amatatsu, K. Morokuma, and S. Yabushita, J. Chem. Phys. 94, 4858 (1991).

${ }^{12}$ D. Townsend, S. K. Lee, and A. G. Suits, J. Phys. Chem. A 108, 8106 (2004).

${ }^{13}$ G. N. A. Van Veen, T. Baller, and A. E. De Vries, Chem. Phys. 92, 59 (1985).

${ }^{14}$ W. P. Hess, D. W. Chandler, and J. J. W. Thoman, Chem. Phys. 163, 277 (1992).

${ }^{15}$ A. T. J. B. Eppink and D. H. Parker, J. Chem. Phys. 109, 4758 (1998); T. K. Kim, K. W. Lee, K.-S. Lee, E. K. Lee, and K.-H. Jung, Chem. Phys. Lett. 446, 31 (2007).

${ }^{16}$ D. Xie, H. Guo, Y. Amatatsu, and R. Kosloff, J. Phys. Chem. A 104, 1009 (2000).

${ }^{17}$ A. B. Alekseyev, H.-P. Liebermann, R. J. Buenker, and N. Y. Sergei, J. Chem. Phys. 126, 234102 (2007).

${ }^{18}$ M. S. Park, K. W. Lee, and K.-H. Jung, J. Chem. Phys. 114, 10368 (2001).

${ }^{19}$ M. L. Lipciuc and M. H. M. Janssen, J. Chem. Phys. 127, 224310 (2007).

${ }^{20}$ J. G. Underwood and I. Powis, Phys. Chem. Chem. Phys. 2, 747 (2000).

${ }^{21}$ A. T. J. B. Eppink and D. H. Parker, Rev. Sci. Instrum. 68, 3477 (1997).

${ }^{22}$ J. W. Hudgens, T. G. DiGiuseppe, and M. C. Lin, J. Chem. Phys. 79, 571 (1983).

${ }^{23}$ A. T. J. B. Eppink and D. H. Parker, J. Chem. Phys. 110, 832 (1999).

${ }^{24}$ J. Danon, H. Zacharias, H. Rottke, and K. H. Welge, J. Chem. Phys. 76, 2399 (1982).

${ }^{25}$ A. T. J. B. Eppink and D. H. Parker, J. Chem. Phys. 110, 832 (1999).

${ }^{26}$ R. Ogorzalek Loo, H. P. Haerri, G. E. Hall, and P. L. Houston, J. Chem. Phys. 90, 4222 (1989).

${ }^{27}$ W. Shiu, J. J. Lin, and K. Liu, Phys. Rev. Lett. 92, 103201 (2004).

${ }^{28}$ I. Powis and J. F. Black, J. Phys. Chem. 93, 2461 (1989).

${ }^{29}$ G. Li, Y. K. Shin, and H. J. Hwang, J. Phys. Chem. A 109, 9226 (2005).

${ }^{30}$ H. W. Hermann and S. R. Leone, J. Chem. Phys. 76, 4766 (1982); C. Yamada, E. Hirota, and K. Kawaguchi, ibid. 75, 5256 (1981).

${ }^{31}$ A. van den Brom, M. L. Lipciuc, and M. H. M. Janssen, Chem. Phys. Lett. 368, 324 (2003).

${ }^{32}$ J. Black and I. Powis, J. Chem. Phys. 89, 3986 (1988).

${ }^{33}$ M. H. M. Janssen, D. H. Parker, G. O. Sitz, S. Stolte, and D. W. Chandler, J. Phys. Chem. A 95, 8007 (1991).

${ }^{34}$ A. C. Kummel, G. O. Sitz, and R. N. Zare, J. Chem. Phys. 85, 6874 (1986). 
${ }^{35}$ T. P. Rakitzis, Chem. Phys. Lett. 342, 121 (2001); R. N. Dixon, J. Chem. Phys. 85, 1866 (1986); T. P. Rakitzis and R. N. Zare, ibid. 110, 3341 (1999).

${ }^{36}$ M. L. Vestal and J. H. Futrell, Chem. Phys. Lett. 28, 559 (1974).

${ }^{37}$ Y. J. Shi, S. Wang, Z. J. Jakubek, and B. Simard, Can. J. Chem. 82, 1077 (2004).

${ }^{38}$ B. P. Tsal, T. Baer, A. S. Werner, and S. F. Lin, J. Phys. Chem. 79, 570 (1975).

${ }^{39}$ Y. Song, X. M. Qian, K. C. Lau, C. Y. Ng, L. Jianbo, and C. Wenwu, J. Chem. Phys. 115, 4095 (2001).

${ }^{40}$ B. Urban and V. E. Bondybey, J. Chem. Phys. 116, 4938 (2002).
${ }^{41}$ A. M. Schulenburg, C. Alcaraz, G. Grassi, and F. Merkt, J. Chem. Phys. 125, 104310 (2006).

${ }^{42}$ I. C. Lane and I. Powis, J. Phys. Chem. 97, 5803 (1993).

${ }^{43}$ X. Liu, R. L. Gross, and A. G. Suits, Science 294, 2527 (2001).

${ }^{44}$ T. N. Olney, G. Cooper, W. Fat Chan, G. R. Burton, C. E. Brion, and K. H. Tan, Chem. Phys. 218, 127 (1997).

${ }^{45}$ G. C. Causley and B. R. Russell, J. Chem. Phys. 62, 848 (1975)

${ }^{46}$ B. Zhang, X. Wang, N. Lou, B. Zhang, and J. Wei, Spectrochim. Acta, Part A 57, 1759 (2001).

${ }^{47}$ D. S. Won, M. S. Kim, J. C. Choe, and T.-K. Ha, J. Chem. Phys. 115, $5454(2001)$ 